\title{
Reseñas
}

Ser de Buenos Aires. Alemanes, argentinos y el surgimiento de una sociedad plural. 1880-1930, Benjamin Bryce

\section{Morello, Juan}

Juan Morello juan.morello79@gmail.com

Universidad Nacional de Tres de Febrero, Argentina

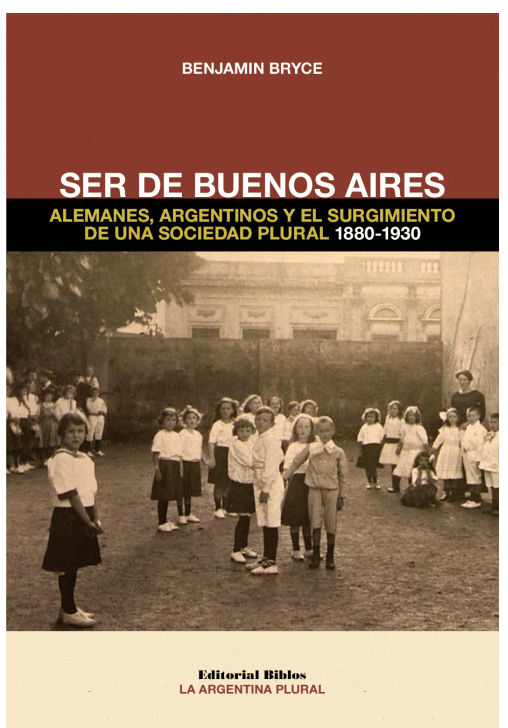

Bryce Benjamin. Ser de Buenos Aires. Alemanes, argentinos y el surgimiento de una sociedad plural. 1880-1930. 2019. Buenos Aires. Editorial Biblos. 336pp.. 978-987-691-756-8

Estudios Sociales. Revista Universitaria Semestral

Universidad Nacional del Litoral, Argentina

ISSN: 0327-4934

ISSN-e: 2250-6950

Periodicidad: Semestral

núm. 61, e0014,2021

estudiossociales@unl.edu.ar

URL: http://portal.amelica.org/ameli/jatsRepo/293/2932743014/ index.html

DOI: https://doi.org/10.14409/es.2021.2.e0014

El contenido está bajo Licencia Creative Commons Atribución-

NoComercial-Compartir Igual 4.0 Internacional. Atribución - No Comercial - Compartir Igual (BY-NC-SA): no se permite un uso comercial de la obra original ni de las posibles obras derivadas, la distribución de las cuales se debe hacer con una licencia igual a la que regula la obra original.

\section{(c) (1) (-)}


La obra de Benjamin Bryce viene a iluminar ciertos aspectos poco transitados por los estudios sobre la inmigración alemana y germanoparlante de Buenos Aires. No es la primera vez que un historiador canadiense se dedica al estudio de los alemanes en Argentina a fines del siglo XIX y principios del XX. Su antecesor, si esta obra resultase en la fundación de una nueva tradición, fue Ronald C. Newton con su libro (nunca traducido al español) German Buenos Aires, 1900-1933. Social Change and Cultural Crisis. ${ }^{1}$ Pero si Newton se ocupó de presentar un panorama general de la comunidad, haciendo foco sobre todo en los conflictos que surgían tanto al interior de una comunidad desigual, como en su interrelación con el "exterior" por momentos muy hostil, sobre todo en contextos como el de la Gran Guerra, Bryce apela a otra perspectiva, que sitúa su análisis en los esfuerzos de esta comunidad por desarrollarse, por generar una identidad propia y por estudiar una serie de acciones que, según el autor, van de acuerdo a la idea de futuro que ella tenía de sí misma.

El estudio de Bryce se corporiza a través del análisis de una gran cantidad de fuentes disponibles no solo en Buenos Aires, sino también en archivos de Berlín, Londres, París y Madrid. En este sentido, cabe destacar que la variedad de este corpus documental enriquece sobremanera las perspectivas a desarrollar. El manejo y el uso de fuentes de difícil acceso (por lo menos para el historiador nativo) le brindan la posibilidad de pensar la comunidad por fuera de su típica idiosincrasia.

Una introducción, una conclusión y seis capítulos que las separan forman el esqueleto de la obra. El primero de los capítulos está dedicado a las sociedades de beneficencia; los tres que continúan, a la educación bilingüe y el papel de la lengua alemana en la comunidad y los dos últimos al accionar de las iglesias protestante y católica. En ellos se analiza el rol de los líderes en las instituciones de asistencia social y cómo intentaron dar forma al concepto de ciudadanía; el papel de la mujer inmigrante en esta nueva comunidad paternalista y patriarcal; la situación de los niños, hijos de inmigrantes no nacidos en Argentina, alumnos de las escuelas bilingües (la mayoría de las cuales todavía existen); el problema de la educación en lengua alemana y los embates del Estado argentino y la labor pastoral de las iglesias luterana y católica junto a las relaciones transatlánticas que tendieron con Alemania.

Los aportes centrales del libro de Bryce se concentran en estudiar, en primer lugar, cuáles eran las perspectivas de futuro de esta comunidad. En este sentido, a partir de un diálogo con las ideas de los historiadores David Engerman y Reinhart Koselleck, Bryce establece que las nociones que tenía la comunidad de su propio futuro -que no se extendía más allá de los diez años- son las que dan una explicación racional a las decisiones que tomaron y a su modo de proceder. En segundo lugar, este accionar es el que crea un «espacio étnico» donde la comunidad generó una identidad propia que dio como resultado una suerte de equilibrio entre «la herencia étnica y la pertenencia a la Argentina» (p. 23). Este equilibrio se plasma en lo que Bryce identifica como «espacios o identidades híbridas» cuyos límites, tanto los de la identidad como los del espacio de la 
comunidad, son siempre difusos. Esto rompe con la idea tradicional que suele tenerse de una comunidad como exclusivamente "alemana" y herméticamente "cerrada" al exterior.

Su estudio de las escuelas bilingües es quizá el mejor ejemplo que sustenta esta hipótesis. Algo clave para muchos sectores de esta comunidad, a fin de mantener una identidad, era el idioma alemán. Las escuelas debían, por ende, ser la herramienta que reforzara tanto el aprendizaje como la utilización del idioma. El resultado fue que la lengua continuó sin poder imponerse, los niños no querían hablarla y si lo hacían era con muchos errores. ¿Se perdió por ello la alemanidad? Tampoco. El resultado se compone de la mezcla de los esfuerzos ligados a la perspectiva de futuro, la voluntad de los propios actores (educadores y estudiantes) y la relación con el exterior (en este caso la Comisión Nacional de Educación y sus intentos por hacer de la lengua castellana la lengua obligatoria, única y hegemónica). Evidentemente la comunidad alemana no puede darse por perdida, pero sí por transformada, algo que intenta abarcar el concepto de hibridación - una suerte de intermedio difuso entre lo alemán y lo argentino-.

En tercer lugar, el libro brinda otro aporte que, sin ser central, enriquece el conjunto de su análisis. El autor aporta una serie de comparaciones de algunos aspectos de la comunidad alemana de Buenos Aires con la estadounidense y la canadiense en ciudades como Nueva York, Chicago, Boston o Toronto. En este sentido, el estudio también es ejemplificador porque revela cómo toma forma la comunidad en relación a un exterior determinado. Este es el caso de los líderes benefactores (varones pudientes) quienes tuvieron mayor preponderancia en Argentina y no tanto en Estados Unidos o Canadá. La explicación a esto reside en que Argentina se caracterizaba por la ausencia de un Estado benefactor que contuviese a la comunidad.

Ser de Buenos Aires abarca un espectro de cincuenta años. En ese período de tiempo, sin embargo, no siempre es fácil interpretar la serie de cambios profundos que se dieron en la sociedad porteña (léase, entre otros, la lucha por una democracia más representativa, el fortalecimiento de la idea de Nación, las convulsiones de la Primera Guerra Mundial y la segunda oleada inmigratoria en el período de entreguerras) y cómo ellos pudieron repercutir en las comunidades de inmigrantes que habitaban en la ciudad. Por momentos, pareciera que el libro tiende a hacer caso omiso de algunas de estas cuestiones. Si la comunidad germanoparlante tenía límites difusos y estaba en constante relación con el exterior no siempre parece verse expuesta a estos vaivenes de la sociedad en la que le tocaba vivir. Por otra parte, cabría preguntarse también cómo encaja el concepto de identidad híbrida en ese período de tiempo. Bryce afirma: «Entre 1880 y 1930, los niños que vivían en Buenos Aires y cuyos padres habían nacido en Europa casi nunca se veían a sí mismos como inmigrantes» (p. 111). Bien vale la pregunta: ¿y si simplemente no lo eran? Por último, el autor otorga una fuerte agencia activa y consciente a la comunidad (sobre todo a sus líderes) cuyo fin era el de forjar una sociedad argentina multilingüe y culturalmente más diversa. Está claro que esa agencia existió. Lo que no siempre se deduce de los ejemplos aportados es si esa agencia fue realmente tan consciente y con un fin tan diáfano. El caso de la comunidad protestante con su fuerte impronta a mantener el idioma alemán y su visión racializada de una alemanidad heredada biológicamente no parece acercarse tanto a ese ideal. 
Estos señalamientos no constituyen, sin embargo, ningún impedimento para no recomendar su lectura, más bien, todo lo contrario. Con una prosa amena (y una excelente traducción), Bryce acompaña e introduce al lector en una historia poco conocida y a la que todavía le queda mucho por investigar, la de la inmigración alemana en Buenos Aires.

\section{Notas}

1. Newton, Ronald C. (1977): German Buenos Aires, 1900 - 1933. Social Change and Cultural Crisis. Austin, University of Texas Press. 